\title{
Biochemical diagnosis of cystinosis using cultured cells
}

\author{
P. WILLCOX and A. D. PATRICK \\ From the Institute of Child Health, University of London
}

\begin{abstract}
Willcox, P., and Patrick, A. D. (1974). Archives of Disease in Childhood, 49, 209. Biochemical diagnosis of cystinosis using cultured cells. A simple method is described for the biochemical diagnosis of cystinosis using small numbers of cells

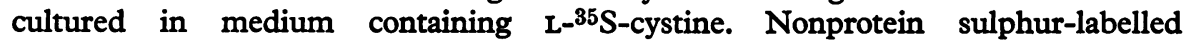
compounds were extracted from the cells and separated by thin-layer chromatography. The abnormally high incorporation of ${ }^{35} \mathrm{~S}$-cystine by cystinotic skin fibroblasts was apparent on visual examination of autoradiographs of the chromatograms and was quantitated by comparison with the incorporation of ${ }^{35} \mathrm{~S}$ into glutathione. The method was used to confirm the diagnosis of 6 cystinotic patients. The incorporation of ${ }^{35} \mathrm{~S}$-cystine by 2 - to 3 -week cultures of control amniotic fluid cells obtained in early pregnancy was similar to that of control skin fibroblasts, suggesting that the method would also be of use in the early prenatal detection of cystinosis.
\end{abstract}

Though the clinical expression of cystinosis ranges from a severe nephropathic infantile form to an adult condition which appears to be totally benign, all cases are characterized biochemically by the accumulation and crystallization of cystine in phagocytic cells of internal organs, cornea, bone marrow, and the lymphatic system. Symptoms of progressive renal tubular dysfunction usually develop from about 6 months of age in the infantile form of the disease, and the presence of crystals in the cornea and bone marrow is then sought to confirm the diagnosis. However, failure to detect crystals in routine preparations of bone marrow sometimes occurs, even for older children in whom crystal deposition would be expected to be coincident with an advanced state of the disease. These failures are undoubtedly in part due to errors of processing, but the earliest stages of the disease at which crystal deposition might first occur have not been clearly defined. It is certain that the cystine content of cystinotic cells may increase to many times normal levels without the formation of crystals; the free-cystine contents of cystinotic leucocytes and skin fibroblasts were found to be, respectively, 80 and 100 times the normal level (Schneider, Bradley, and Seegmiller, 1967a; Schneider et al., 1967b). The demonstration of increased free-cystine levels in cystinotic cells, rather than the presence of cystine crystals, thus

Received 3 September 1973. appears to be a more reliable biochemical index of cystinosis.

Measurement of cystine has usually involved its separation by ion-exchange chromatography on an amino acid analyser incorporating colorimetric analysis, a relatively insensitive procedure requiring large numbers of cells. Alternatively, cells have been pulse-labelled with ${ }^{35} \mathrm{~S}$-cystine and the column effluent monitored on passing through an anthracene-packed flow cell in a scintillation counter (Schneider, Bradley, and Seegmiller, 1968). This procedure is highly sensitive but requires equipment not generally available.

We report a simpler method of biochemical diagnosis employing thin-layer chromatography for the separation of cystine in extracts of ${ }^{35} \mathrm{~S}$-cystinelabelled cultured cells, followed by scintillation counting of chromatograms or densitometric scanning of autoradiographs for the estimation of ${ }^{35} \mathrm{~S}$-cystine incorporation.

\section{Methods}

Skin fibroblast cultures were obtained by standard procedures. Amniotic fluid cell cultures were obtained by a method similar to that of Nadler and Gerbie (1970). Cultures were maintained on medium 199 (Wellcome) containing antibiotics (penicillin 100 units $/ \mathrm{ml}$, streptomycin 100 units $/ \mathrm{ml}$ ), added glutamine ( $1 \mathrm{mmol} / 1$.) and $15 \%$ fetal bovine serum (Flow Laboratories) in an atmosphere of $5 \% \mathrm{CO}_{2}-95 \%$ air at $37^{\circ}$. All radioactive experiments were carried out using $50 \mathrm{~mm} \times 13 \mathrm{~mm}$ disposable Petri dishes (Sterilin). 
Skin fibroblast cultures of various ages (1-10 subcultures) were used for the estimation of cystine incorporation. Results were not influenced by the age of the culture. For the estimation of cystine content the cultures were finally grown for 2 to 3 days on medium in which L-35 S-cystine (final specific activity 10-70 $\mathrm{mCi} / \mathrm{mmol}$ ) replaced unlabelled cystine. After removal of the medium, the cell layer was washed twice with trypsin solution $(0.1 \%)$ and then trypsinized. The cell suspension was transferred in $5 \mathrm{ml}$ of normal culture medium to a $10 \mathrm{ml}$ conical glass tube, centrifuged, and the cell pellet was washed four times with $6 \mathrm{ml}$ ice-cold saline $(0.9 \% \mathrm{w} / \mathrm{v})$. After the final wash, $0.2 \mathrm{ml}$ freshly prepared $2 \mathrm{mmol} / \mathrm{l}$. N-ethylmaleamide (NEM) in 2 $\mathrm{mmol} / \mathrm{l}$. sodium phosphate buffer, $p \mathrm{H} 6 \cdot 4$, was added to the pellet. The suspended cells were subjected to mild sonication and left for 2 minutes at $0^{\circ}$. Sulphosalicylic acid $(5 \% \mathrm{w} / \mathrm{v}, 25 \mu \mathrm{l})$ was then added and the precipitated protein removed by centrifugation.

The supernatant fluid was analysed by thin-layer chromatography on pre-coated microgranular cellulose plates (F1440, Schleicher and Schull).

Samples containing 10,20 , and $30 \mu$ l supernatant were applied as $1 \mathrm{~cm}$ streaks and developed in the solvent system, $\mathrm{n}$-butanol : pyridine : acetic acid : water $(30: 20: 6$ : 24 by volume). A $10 \mathrm{~cm}$ run was sufficient to achieve good separation of all labelled components. The plates were air-dried and then exposed to Kodirex $x$-ray film (Kodak) for 1 to 3 days. Though visual examination of the developed film was sufficient to distinguish cystinotic samples from controls, an estimate of ${ }^{35} \mathrm{~S}$-cystine incorporation was obtained in two ways: (a) by densitometric scanning of the negative film, (b) by scintillation counting of the cystine and glutathione-NEM areas cut from the chromatogram and added to scintillation fluid $(10 \mathrm{ml})$. In each case the level of ${ }^{35} \mathrm{~S}$-cystine incorporation was expressed as the ratio ${ }^{35} \mathrm{~S}$-cystine: ${ }^{35}$ S-glutathione-NEM (Schulman et al., 1970).

\section{Results and discussion}

The procedure described has been applied to skin fibroblast cultures derived from 6 cystinotic patients, 6 parents, and 6 controls. The results are summarized in Table I. Typical autoradiographic records and their densitometric scans from cystinotic, heterozygote, and control fibroblast specimens are shown in the Fig. In all cases visual examination of autoradiographs readily distinguished homozygous cystinotic from heterozygote and control fibroblasts, and appears to be a simple and reliable method of diagnosis applicable to small numbers (approximately $10^{4}$ ) of cells derived from short-term cultures. The cystinotic abnormality is also clearly shown in the comparative estimates of ${ }^{35} \mathrm{~S}$-cystine incorporation (Table I), for which good agreement between scintillation counting and densitometric scanning methods was obtained. For these small numbers of cells, however, the technique failed to distinguish between heterozygote and
TABLE I

Incorporation of ${ }^{35}$ S-cystine into cultured skin fibroblasts

\begin{tabular}{|c|c|c|c|c|}
\hline \multirow{4}{*}{ Subjects } & \multirow{2}{*}{\multicolumn{4}{|c|}{$\frac{{ }^{35} \text { S-cystine }}{35 \text { S-glutathione-NEM }} \times 100$}} \\
\hline & & & & \\
\hline & \multicolumn{2}{|c|}{$\begin{array}{l}\text { Scintillation } \\
\text { counting }\end{array}$} & \multicolumn{2}{|c|}{$\begin{array}{l}\text { Densitometric } \\
\text { scanningt }\end{array}$} \\
\hline & Range & (mean) & Range & (mean) \\
\hline $\begin{array}{l}\text { Cystinotic patients (6) } \\
6 \text { mth-9 yr of age } \\
\text { Parents of patients (6) } \\
\text { Controls (6) }\end{array}$ & $\begin{array}{c}87-189 \\
8-28 \\
5-18\end{array}$ & $\begin{array}{r}(117) \\
(19) \\
(12)\end{array}$ & $\begin{aligned} & 74-148 \\
< & 5 \ddagger-13 \\
< & 5 \ddagger-10\end{aligned}$ & $\begin{array}{r}(105) \\
(7) \\
(6)\end{array}$ \\
\hline
\end{tabular}

*Counts/minute ratio.

tPeak height ratio.

$\ddagger$ Lower limit of sensitivity.

control specimens. Using relatively large numbers of cells, Schneider et al. (1967a, b) clearly showed that the free-cystine contents of heterozygous cystinotic leucocytes and fibroblasts were significantly greater than normal, though it was apparent that individual cases might not be differentiated owing to some overlap of control and heterozygous ranges. The same conclusion was reached by Kroll et al. (1973). Elucidation of the presumed primary enzyme defect and the development of a sensitive method of assay will perhaps provide a more reliable means of heterozygote detection.

Currently there is no proven treatment with drugs for effectively reversing the accumulation of cystine by cystinotic tissues, and dietary treatment appears to be of little benefit even when instituted early. Nevertheless, the earliest possible diagnosis of an affected infant will be a necessary prerequisite for the success of any effective future therapeutic measure and is an advantage in the symptomatic treatment of infant sibs of cystinotic patients. Measurement of cystine accumulation by cultured cells, for example fibroblasts derived from the umbilical cord, provides this means of earliest diagnosis.

The procedure also extends to a positive control of the disease by detection of the abnormality in cultured amniotic fluid cells obtained by amniocentesis at an early stage of a pregnancy at risk. Schulman et al. (1970) reported the prenatal detection of a probable heterozygote after 7 to 8 weeks of cell culture, and subsequently confirmed the diagnosis using fibroblasts cultured from the umbilical cord. Recently, Schneider et al. (1973) reported the detection of a homozygous fetus, predicted after 6 weeks of cell culture and confirmed 

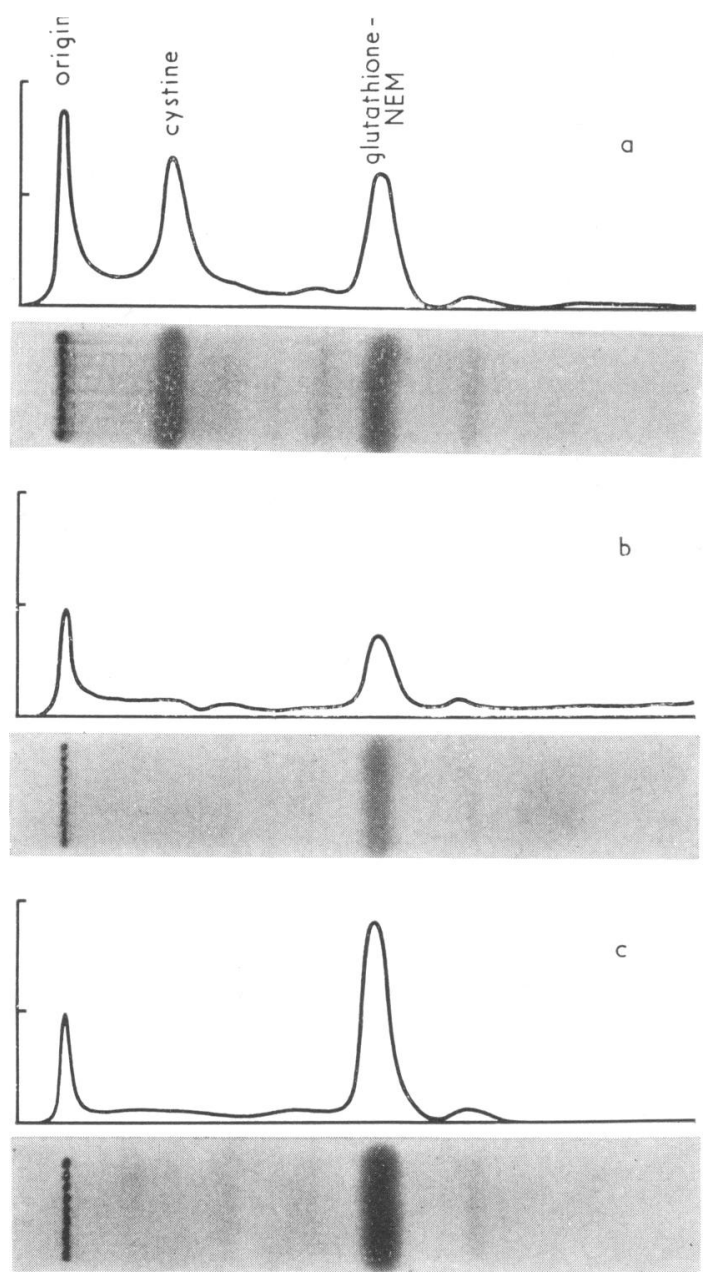

FIG.-Incorporation of ${ }^{35} S$-cystine by cultured fibroblasts. Densitometric scans of autoradiographs after chromatographic separation of ${ }^{35} S$-labelled compounds. (a) Cystinotic, (b) heterozygous, (c) control.

on examination of the fetal tissues after termination of the pregnancy in the 23rd week. No cystine crystals were observed in alcohol-fixed tissue from any organs but the free-cystine content was 50 to 100 times greater than control values. This successful diagnosis suggests that the cystinotic defect is fully manifested by fetal cells in early pregnancy. However, the time required to culture the relatively large numbers of amniotic fluid cells required for assay is a major current problem in the prenatal detection of genetic metabolic disorders. It appears likely that this difficulty will be largely resolved by the development of more sensitive assay procedures for use with small numbers of cells, and it seems that the simple chromatographic separation and estimation of cystine described above provides adequate means of achieving this for cystinosis. The incorporation of ${ }^{35} \mathrm{~S}$-cystine into control amniotic fluid cell cultures is summarized in Table II. The absolute levels and ratios of incorporation were very similar to those found for control skin fibroblasts and were easily determined for fewer than $10^{4}$ cells obtained after only two weeks of culture. Prenatal detection of cystinosis and consideration of termination by 16 weeks thus seems feasible.

The relative ease of the assay procedure warrants its use also for more general investigations of cystinosis, particularly concerning therapeutic measures designed to remove or prevent the accumulation of intracellular cystine. Goldman et al. (1970) showed the removal of cystine from cystinotic fibroblasts by dithiothreitol, a finding confirmed in this laboratory and by Verroust and Schneider (1973). The intracellular location of cystine deposits within the lysosomes of cystinotic cells is a further important factor in the design of such therapeutic measures that might best be considered with the use of fibroblast cultures. It is also possible that cross-correction of cystinotic

TABLE II

Incorporation of ${ }^{35} S$-cystine into cultured amniotic fluid cells

\begin{tabular}{|c|c|c|c|c|}
\hline \multirow[t]{2}{*}{ Specimen } & \multirow[t]{2}{*}{ Gestational age (wk) } & \multirow[t]{2}{*}{ Period of culture $(d y)^{\star}$} & \multicolumn{2}{|c|}{$\frac{{ }^{35} \text { S-cystine }}{{ }^{35} \text { S-glutathione-NEM }} \times 100$} \\
\hline & & & Scintillation counting $\dagger$ & $\begin{array}{c}\text { Densitometric } \\
\text { scanning } \ddagger\end{array}$ \\
\hline $\begin{array}{l}\text { Control } 1 \\
\text { Control } 2 \\
\text { Control } 3\end{array}$ & $\begin{array}{l}14 \\
14 \\
10\end{array}$ & $\begin{array}{l}21 \\
15 \\
14\end{array}$ & $\begin{array}{l}8 \\
9 \\
6\end{array}$ & $\begin{array}{l}<5 \S \\
6 \\
<5 \S\end{array}$ \\
\hline
\end{tabular}

$\star$ Results obtained 1 day after harvest of cells.

tCounts/minute ratio.

$\ddagger$ Peak height ratio.

$\S$ Lower limit of sensitivity. 
fibroblasts by normal fibroblasts in cultures of mixed cell populations, as shown for the mucopolysaccharidoses by Fratantoni, Hall, and Neufeld (1968), will aid our understanding of the primary cause of the disease.

We are indebted to the British Tay-Sachs Foundation for financial support.

\section{REFERENCES}

Fratantoni, J. C., Hall, C. W., and Neufeld, E. F. (1968). Defect in Hurler's and Hunter's syndromes; faulty degradation of mucopolysaccharide. Proceedings of the National Academy of Sciences of the U.S.A., 60, 699.

Goldman, H., Scriver, C. R., Aaron, K., and Pinsky, L. (1970). Use of dithiothreitol to correct cystine storage in cultured cystinotic fibroblasts. Lancet, $1,811$.

Kroll, W., Lichte, K-H., Lutz, P., and Maurer, R. (1973). Cystinosis: quantitative assay of cystine accumulation of homozygotes and heterozygotes. Humangenetik, 17, 337.

Nadler, H. L., and Gerbie, A. B. (1970). Role of amniocentesis in the intrauterine detection of genetic disorders. New England fournal of Medicine, 282, 596.
Schneider, J. A., Bradley, K., and Seegmiller, J. E. (1967a). Increased cystine in leucocytes from individuals homozygous and heterozygous for cystinosis. Science, 157, 1321.

Schneider, J. A., Bradley, K. H., and Seegmiller, J. E. (1968). Transport and intracellular fate of cysteine- ${ }^{35} \mathrm{~S}$ in leukocytes from normal subjects and patients with cystinosis. Pediatric Research, 2, 441.

Schneider, J. A., Rosenbloom, F, M. Bradley, K. H, and Seegmiller, J. E. (1967b). Increased free-cystine content of fibroblasts cultured from patients with cystinosis. Biochemical and Biophysical Research Communications, 29, 527.

Schneider, J. A., Verroust, F. M., Garvin, A. J., Horger, E. O., and Jacobson, C. (1973). The prenatal diagnosis of cystinosis. (Abst.) Pediatric Research, 7, 291.

Schulman, J. D., Fujimoto, W. Y., Bradley, K. H., and Seegmiller, J. E. (1970). Identification of heterozygous genotype for cystinosis in utero by a new pulse-labeling technique. Preliminary report. Fournal of Pediatrics, 77, 468.

Verroust, F. M., and Schneider, J. A. (1973). The effect of dithiothreitol on cystinotic and control fibroblasts in culture. (Abst.) Pediatric Research, 7, 395.

Correspondence to Dr. A D. Patrick, Institute of Child Health, 30 Guilford Street, London WC1N $1 E H$. 